\title{
Transplante de medula óssea em
} leucemia mielóide aguda - Resultados preliminares do Grupo Cooperativo Brasileiro

\section{Bone marrow transplantation in acute myelogenous leukemia - Preliminary results of the Brazilian Cooperative Group}

Daniel G Tabak

O tratamento quimioterápico moderno é capaz de induzir a remissão em cerca de $80 \%$ dos adultos portadores de leucemia mielóide aguda (LMA). A maioria dos pacientes, entretanto, apresentará uma recidiva caso nenhum tratamento de consolidação seja instituído. Embora o transplante alogênico (TMO alo) seja reservado para os mais jovens, com fatores prognósticos desfavoráveis, esta estratégia apresenta limitações - menos de $40 \%$ possui um doador familiar compatível. Aqueles que não possuem um doador são habitualmente encaminhados para o transplante autólogo (TMO auto) ou são tratados com quimioterapia convencional, enquanto a busca por um doador não aparentado é conduzida. As dúvidas sobre qual a melhor estratégia a ser adotada permanecem, apesar dos inúmeros estudos publicados na literatura.

No Brasil, a situação é ainda mais complexa. Dados concretos sobre a incidência desta patologia e do número de candidatos às diversas modalidades terapêuticas inexistem. $\mathrm{O}$ acesso dos pacientes às instituições capazes de reproduzir os resultados positivos no tratamento inicial da LMA é muito limitado. A seleção de pacientes encaminhados para o transplante em nosso país é, portanto, distinta daquela que caracteriza os estudos internacionais. Diante deste quadro extremamente complexo, Hamerschlak e cols ${ }^{1}$ devem ser parabenizados por apresentar os resultados do transplante de medula óssea para a LMA no Brasil. A reprodutibilidade dos resultados obtidos nos centros internacionais reflete a maturidade atingida pela comunidade transplantadora brasileira ao atingir os 27 anos de existência. O estudo cria ainda a oportunidade para analisarmos a nossa estratégia no manuseio destes pacientes.

Quando deve ser indicado o TMO alo em portadores de LMA? Qual o papel do TMO auto na consolidação? Qual a melhor forma de condicionamento? Quando iniciar a busca por um doador não aparentado? Neste breve comentário, apenas alguns fatores serão considerados.

Os autores realizaram uma análise retrospectiva a partir de um questionário submetido aos diversos centros transplantadores. Como em todos os estudos não randomizados, este grupo de pacientes selecionados para o transplante representa um grupo especial. Habitualmente, pacientes jovens em boas condições clínicas são encaminhados para o transplante em primeira remissão. Pacientes que apresentam uma recidiva precoce, ou toxicidade excessiva após o tratamento inicial, são excluídos desta estratégia. Um viés de tempo passa a ser introduzido: pacientes transplantados em primeira remissão precisam sobreviver o tempo necessário para receber aquela modalidade terapêutica. No estudo do Medical Research Council - AML 10, por exemplo, os pacientes de alto risco apresentaram uma taxa de recidiva de $32 \%$ nos primeiros seis meses de evolução. Desta forma, os pacientes de alto risco, transplantados ainda em primeira remissão, representam um grupo com um prognóstico mais favorável. Este problema no Brasil é amplificado pelo acesso limitado dos pacientes, não apenas aos centros de transplante, mas também a um tratamento inicial adequado. Este fato pode ser corroborado por este estudo, no qual mais de $90 \%$ dos pacientes analisados são oriundos dos estados de São Paulo e Paraná. O acesso limitado ao tratamento alocado também ocorre em pacientes submetidos ao TMO auto. Na metanálise publicada por Nathan e cols ${ }^{2}$ incluindo mais de 4 mil pacientes portadores de LMA, apenas 69\% foram de fato transplantados. Aquele estudo, entretanto, demonstrou que 92\% dos pacientes alocados para a consolidação com quimioterapia foram realmente tratados. A análise por intenção de tratar e a randomização "genética" (baseada na disponibilidade de um doador) podem minimizar o viés do tempo, embora o valor real do transplante possa ser subestimado.

No estudo brasileiro, os pacientes alocados para o TMO auto apresentavam ainda uma particularidade adicional: 24\% eram portadores de leucemia promielocítica. Atualmente, a maioria dos pacientes portadores de LMA-M3 é curada com o tratamento convencional. A seleção destes pacientes deve ser considerada no contexto histórico quando a maioria dos pacientes não tinha acesso ao tratamento com o ácido transretinóico e ao suporte hemoterápico moderno que mudaram as expectativas naquela patologia. Ainda no estudo de Nathan e cols, o pequeno incremento na sobrevida livre de eventos associada com o TMO auto em CR1 não se traduziu em um aumento da sobrevida global, quando comparado com a quimioterapia convencional. Observou-se não apenas uma taxa de recidiva elevada, mas também maior toxicidade associada ao transplante. Os números no estudo brasileiro também são significativos e certamente refletem a curva do aprendizado, principalmente considerando que 78\% dos pacientes receberam precursores hematopoéticos de sangue periférico, isoladamente ou associados a células de medula óssea.

O TMO auto em CR1 no tratamento da LMA não deve, entretanto, ser desconsiderado. O grupo cooperativo alemão ${ }^{3}$ apresentou recentemente um estudo prospectivo comparando o uso de altas doses de ARA-C e o transplante de precursores hematopoéticos de sangue periférico como consolidação tardia em pacientes portadores de LMA com idade inferior a 60 anos. A análise citogenética foi crítica para definir os resultados. Pacientes classificados como de risco padrão - t(8;21), inv(16) ou cariótipo normal e $<5 \%$ de blastos na medula óssea do d15 da indução - apresentaram uma sobrevida global semelhante, independente da forma de consolidação. Entretanto, os autores apontaram o TMO auto como o tratamento de escolha devido a menor toxicidade 
associada ao tratamento. O mesmo benefício não pode ser demonstrado para pacientes de alto risco, para os quais o grupo recomenda o TMO alo.

Na experiência brasileira, o TMO alo foi realizado em CR1 em 40\% dos pacientes; porém, os dados citogenéticos foram analisados em apenas 30\% dos pacientes. Dois estudos recentes ressaltam de forma dramática a importância da análise molecular para a decisão terapêutica. Schlenk e cols demonstraram que o impacto prognóstico negativo, determinado pela presença da ITD-FLT3, pode ser neutralizado pelo TMO alo. ${ }^{4}$ No entanto, o valor preditivo da alteração molecular mais comum na LMA ainda não pode ser completamente estabelecido. ${ }^{5}$

O valor imunoterapêutico do transplante alogênico é inquestionável. Entretanto, a morbidade associada à DECH e às infecções limita a sua maior aplicabilidade. Portanto, a seleção de pacientes não deve ser determinada apenas pelo risco do processo biológico, mas também pelo risco de toxicidade associada ao procedimento. Como quantificar este risco? Sorror e cols, ${ }^{6}$ em Seatlle, descreveram recentemente um índice específico de comorbidade para pacientes submetidos ao transplante hematopoético. A aplicabilidade deste índice, que ressalta inclusive a importância de fatores como a obesidade e aspectos psiquiátricos, pode permitir o melhor aconselhamento aos pacientes antes do TMO e também deveria ser estudado na nossa população.

No estudo brasileiro, a maioria dos pacientes submetidos ao TMO alo não se encontrava em primeira remissão. Nesta fase, a indicação do transplante é menos complexa, diante da limitação terapêutica com potencial curativo. Este benefício pode ser quantificado? Breems e cols ${ }^{7}$ acreditam que sim. Um índice prognóstico foi estabelecido com a análise de 667 pacientes portadores de LMA não M3. Os seguintes indicadores foram incluídos: intervalo entre a primeira recidiva e a primeira remissão; citogenética ao diagnóstico; idade na recidiva e realização de transplante hematopoético prévio. Foram identificados três grupos de risco com uma probabilidade de sobrevida significativamente distinta de $46 \%, 18 \%$ e $4 \%$ em cinco anos. Este modelo também poderia ser analisado em nossa população e talvez ajudar na seleção de pacientes quando os recursos são ainda mais limitados.

Qual o impacto do transplante na qualidade de vida de portadores de leucemia mielóide aguda? Dados específicos para portadores de LMA em CR1 são limitados. O intergrupo alemão ${ }^{8}$ apresentou recentemente uma análise de 525 questionários aplicados a pacientes com idade mediana de 46 anos e acompanhados por um período mediano de nove anos. Foram transplantados 244 pacientes (alo: 189; auto: 55) e 281 pacientes tratados com quimioterapia convencional. Problemas na vida social, familiar e na atividade econômica comprometeram mais significativamente os pacientes submetidos ao TMO alo. Estes aspectos devem ser valorizados ao serem consideradas as opções terapêuticas.

Vários fatores contribuíram para a redução da mortalidade associada aos transplantes hematopoéticos na última década e também vêm sendo incorporados pelo grupo brasileiro: 1) Monitorização molecular e tratamento preemptivo de infecções por CMV; 2) Doses mais elevadas de precursores hematopoéticos; 3) Novos agentes antifúngicos; 4) Melhor seleção de doadores não aparentados através da tipagem HLA molecular de alta resolução; 5) Uso mais racional da infusão de linfócitos na prevenção e tratamento de recidivas e 6) Utilização de regimes não mieloablativos permitindo inclusive a realização do transplante em pacientes com idade superior a 60 anos. O tratamento da LMA deverá se modificar nos próximos anos. Novos agentes terapêuticos como os anticorpos monoclonais, inibidores da transdução de sinais e da angiogênese, estão sendo rapidamente incorporados em nosso arsenal e poderão modificar as recomendações terapêuticas no manuseio da LMA. O estudo de Hamerschlak e cols deverá servir como uma plataforma para novos estudos, que ampliarão o horizonte da pesquisa clínica em LMA no Brasil.

\section{Referências Bibliográficas}

1. Hamerschlak N, Barton D, Pasquini R et al. Um estudo retrospectivo do tratamento de leucemia mielóide aguda com o Transplante de Medula óssea - A experiência Brasileira. Rev Bras Hematol Hemoter 2006;28(1):11-18.

2. Nathan PC, Sung L, Crump M et al. Consolidation therapy with autologous bone marrow transplantation in adults with acute myeloid leukemia: a meta-analysis. J Natl Cancer Inst 2004;96(1):38-45.

3. Ganser A, Krauter J, Hoelzer D et al. Prospective randomized comparison of high dose AraC and autologous peripheral blood stem cell transplantation as late consolidation for patients $\leq 60$ years with standard risk AML. Blood 2005;106(11):48a.

4. Schlenk RF, Krauter J, Fröhling S et al. Postremission therapy with an allogeneic transplantation from an HLA- Matched family donor seems to overcome the negative prognostic impact of FLT3-ITD in younger patients with acute myeloid leukemia exhibiting a normal karyotype. Blood 2005;106(11):662a.

5. Gale RE, Hills R, Kottaridis PD et al. No evidence that FLT3 status should be considered as an indicator for transplantation in acute myeloid leukemia (AML): an analysis of 1135 patients, excluding acute promyelocytic leukemia, from the UK MRC AML10 and 12 trials. Blood 2005;106(10):3.658-65.

6. Sorror ML, Maris MB, Storb R et al. Hematopoietic cell transplantation (HCT)-specific comorbidity index: a new tool for risk assessment before allogeneic HCT. Blood 2005;106(8):2.912-9.

7. Breems DA, Van Putten WL, Huijgens PC et al. Prognostic index for adult patients with acute myeloid leukemia in first relapse. J Clin Oncol 2005;23(9):1.969-78.

8. Messerer D, Engel J, Hasford J, et al. Allogeneic transplantation from an HLA - Matched family donor in first complete remission of acute myeloid leukemia had an adverse impact on quality of life in patients followed for at least five years after treatment: A survey of the german AML Intergroup on 525 Patients. Blood 2005;106(11):221a.

Avaliação: O tema abordado foi sugerido e avaliado pelo editor.

Conflito de interesse: não declarado

Recebido 13/01/2006

Aceito: 16/01/2006

Daniel G. Tabak

Coordenador do Programa de Terapia Celular

Clínica São Vicente, Rio de Janeiro

Correspondência para: Praia de Botafogo, 228 - Sala 1004

Rio de Janeiro, RJ - Brasil

E-mail:dantabak@terra.com.br 